\title{
Hyperuricemia and Impaired Renal Function: A Prospective Cohort Study
}

\author{
Noppawit Aiumtrakul Puvanant Wiputhanuphongs Ouppatham Supasyndh \\ Bancha Satirapoj \\ Department of Medicine, Phramongkutklao Hospital and College of Medicine, Bangkok, Thailand
}

\section{Keywords}

Glomerular filtration rate $\cdot$ Hyperuricemia

\begin{abstract}
Background: Related studies have demonstrated a relationship of elevated serum uric levels with a decline in kidney function. However, limited evidence exists in a Southeast Asian community-based population. Objective: The study aimed to examine the relationship between serum uric acid levels and impaired renal function. Methods: A prospective cohort study was conducted in the Thai army health checkup population between July 1, 2006 and December 31, 2012. Inclusion criteria included age older than 20 years and baseline estimated glomerular filtration rate (eGFR) over $60 \mathrm{~mL} /$ $\mathrm{min} / 1.73 \mathrm{~m}^{2}$. Cox regression analysis was used to evaluate the association between incidence of impaired renal function and baseline serum uric acid quartiles. Impaired renal function was defined as eGFR $<60 \mathrm{~mL} / \mathrm{min} / 1.73 \mathrm{~m}^{2}$ over 3 months. Results: A total of 9,534 participants (7,474 men and 2,060 women) were enrolled. Cox regression analysis revealed a significant association of serum uric acid level with impaired renal function in the whole population as the unadjusted hazard ratio (HR) $(95 \% \mathrm{Cl})$ of impaired renal func-
\end{abstract}

tion in second, third, and fourth quartiles were 2.1 (1.39, $3.17), 2.39$ (1.6, 3.59), and 3.94 (2.71, 5.74), respectively, when compared with serum uric acid in the first quartile, respectively. After adjusting in 2 models, the HR still significantly persisted with similar magnitudes in all quartiles. Higher incidences of impaired renal function were observed among males than among females in all quartiles. Kaplan-Meier curve showed better renal survival rate in the lower quartile groups. Linear regression analysis showed that eGFR negatively correlated with serum uric acid $(r=-0.213, p<0.001)$. Conclusion: Our study suggests that an independent association exists of serum uric acid levels with the incidence of impaired renal function and renal progression in the Southeast Asian community-based population.

$$
\begin{aligned}
& \text { (c) } 2020 \text { The Author(s) } \\
& \text { Published by S. Karger AG, Basel }
\end{aligned}
$$

\section{Introduction}

CKD has been proven as a risk factor for cardiovascular disease and mortality [1]. It has a high global prevalence, causing high economic costs to health systems [2, 3 ], and $\mathrm{CKD}$ often progresses to ESRD, requiring renal karger@karger.com www.karger.com/kdd

Karger $\frac{1}{\%}$

马OPEN ACCESS
(C) 2020 The Author(s)

Published by S. Karger AG, Basel

This article is licensed under the Creative Commons AttributionNonCommercial-NoDerivatives 4.0 International License (CC BYNC-ND) (http://www.karger.com/Services/OpenAccessLicense) Usage and distribution for commercial purposes as well as any distribution of modified material requires written permission.
Noppawit Aiumtrakul

Department of Medicine, Phramongkutklao College of Medicine Ratchawithi Rd., Thung Phaya Thai

Bangkok 10400 (Thailand)

tan.niie@me.com 
replacement therapy [4]. Risk factors that are identified with an early intervention may slow the progression of CKD. The most common established risk factors for CKD are diabetes and hypertension [5]. Although uric acid is not considered as the most important cause, increase of serum uric acid is associated with elevated blood pressure (BP), hypertension, diabetes, and renal diseases [6-9]. Chronic hyperuricemia is also strongly associated with chronic tubulointerstitial disease, and many of these patients have deteriorated kidney function $[10,11]$.

Animal model studies have shown the effect of hyperuricemia on renal progression through a potential mechanism linked to increased systemic BP and cyclooxygenase-2-mediated, thromboxane-induced vascular disease [12], and microvascular changes leading to endothelial dysfunction [13]. Many related studies have demonstrated a relationship of elevated serum uric levels with a decline in kidney function [14-18]. However, limited evidence is available in Southeast Asian community-based populations, where the setting of various genetic and ethnic factors differs from that in Western countries. To fill this gap, this study was conducted to examine the relationship between serum uric acid levels and renal outcomes in a Thai population.

\section{Materials and Methods}

\section{Subjects}

A prospective cohort study was conducted in the Thai army annual health checkup population from July 1, 2006, to December 31, 2012, at Phramongkutklao Hospital, Bangkok, Thailand. The study protocol was approved by the Institutional Review Board of Royal Thai Army Medical Department's committee on human research, and written informed consent was obtained from all patients. Random samples of individuals aged over 20 years and baseline estimated glomerular filtration rate (eGFR) over $60 \mathrm{~mL} /$ $\mathrm{min} / 1.73 \mathrm{~m}^{2}$ were reviewed to retrieve medical and personal data, including baseline demographic characteristics and comorbidities. Patients with acute kidney injury within 3 months at enrollment in the study were excluded. In all, 17,850 from 23,712 individuals were eligible for age and eGFR screening, but 8,316 subjects had incomplete information throughout 6 years' follow-up. Thus, 9,534 participants (7,474 men and 2,060 women) were enrolled.

The primary outcome was impaired renal function, defined by eGFR $<60 \mathrm{~mL} / \mathrm{min} / 1.73 \mathrm{~m}^{2}$ over 3 months. Renal survival was time to eGFR $<60 \mathrm{~mL} / \mathrm{min} / 1.73 \mathrm{~m}^{2}$ over 3 months. Subjects not reaching an event were censored at the date of last follow-up visit. Criteria to diagnose type 2 diabetes in the study were fasting plasma glucose $(\mathrm{FPG}) \geq 126 \mathrm{mg} / \mathrm{dL}$ at least twice and random plasma glucose $\geq 200 \mathrm{mg} / \mathrm{dL}$ with diabetic symptoms according to the American Diabetes Association: clinical practice recommendations 2005 [19]. For hypertension, diagnostic criteria were from office blood pressure measurement with systolic $\geq 140 \mathrm{~mm} \mathrm{Hg}$ or diastolic $\geq 90 \mathrm{~mm} \mathrm{Hg}$ according to the Seventh Report of the Joint National Committee on Prevention, Detection, Evaluation, and Treatment of High Blood Pressure (JNC 7) [20].

\section{Data Collection}

Personal data were obtained by reviewing electronic medical records in the hospital database. At baseline, information on age, sex, smoking history, alcohol consumption, regular exercise, and underlying diseases including type 2 diabetes, hypertension, and dyslipidemia were recorded. A physical examination was conducted for all participants, including BP, bodyweight, height, waist circumference, and BMI. Subjects were asked for 12-h overnight fasting before blood samples were drawn. Serum $\mathrm{Cr}$, BUN, eGFR, serum uric acid, total cholesterol, high-density lipoprotein cholesterol (HDL), low-density lipoprotein cholesterol (LDL), triglycerides, FPG, serum aspartate aminotransferase (AST), alanine aminotransferase (ALT), alkaline phosphatase, and hemoglobin were measured. Serum $\mathrm{Cr}$ was tested using the enzymatic method, and BUN was tested using a kinetic test with the urease method. eGFR was calculated using the Chronic Kidney Disease Epidemiology Collaboration (CKD-EPI) equation. The examination interval of regular health checkup was annual and varied between July and December of each years from 2006 to 2012 .

\section{Statistical Analysis}

Continuous data were reported as means and standard deviation, and categorical data were reported as number with percentage (\%). Comparisons between serum uric acid quartiles were made using ANOVA tests, as appropriate, for continuous variables and by $\chi^{2}$ test for categorical variables. Mean change of characteristics at the end of the study was calculated by last minus baseline value of each continuous variables and made using repeated ANOVA test. Annual changes of mean eGFR with $95 \%$ confidence intervals (CI) were calculated by the mean change divided by followup time (years). A multivariate analysis of serum uric acid levels on impaired renal function was calculated with the hazard ratio (HR) with 95\% CI, involving survival time to the first diagnosis of impaired renal function in any individual subject. Cox regression model was performed on total subjects and each sex to predict impaired renal function and dropout. The included covariates of Model 1 were age, BMI, sex, type 2 diabetes, hypertension, smoking, and alcohol consumption. For Model 2, age, BMI, sex, type 2 diabetes, hypertension, triglyceride, HDL, AST, alkaline phosphatase, hemoglobin, smoking, alcohol consumption, and exercise were included. Progression of kidney function over time was illustrated in annual mean eGFR with 95\% CI according to serum uric acid level quartiles. The Kaplan-Meier model and log-rank statistics were used to analyze renal survival according to uric acid level quartiles. Correlation coefficients between baseline serum uric acid levels and eGFR at the end of the study were calculated using simple regression analysis. Incidence of impaired renal function was calculated as the number of new cases of impaired renal function per number of person-years at risk according to quartiles of baseline serum uric acid levels and sex. All $p$ values were 2 -sided, and $p$ value $<0.05$ was set to indicate statistical significance. All analyses were performed using SPSS 22.0 (SPSS, Chicago, IL, USA). 
Table 1. Baseline characteristics of serum uric acid quartiles

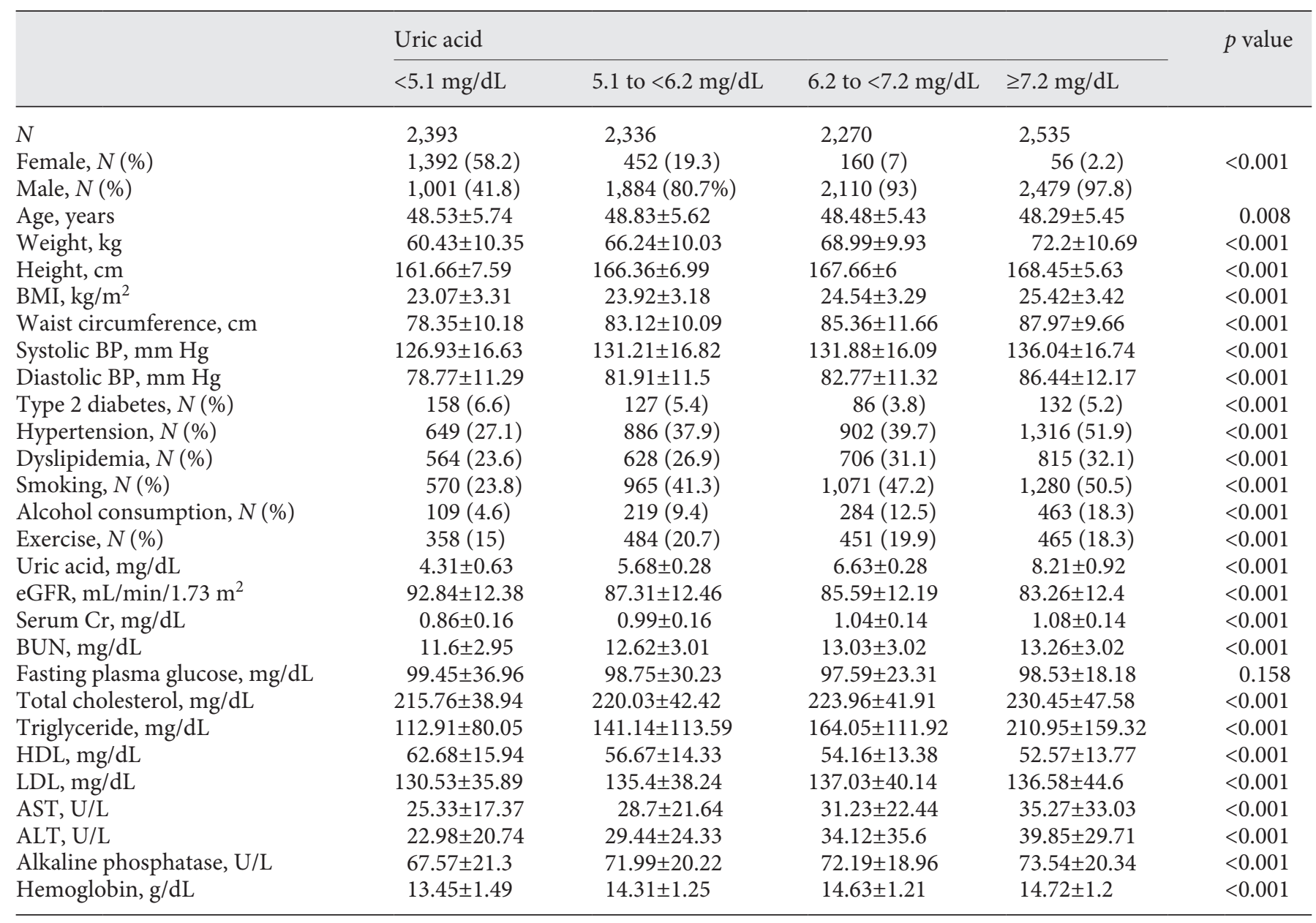

Data are presented as mean $\pm \mathrm{SD}$, and number with percentage. ALT, alanine transaminase; AST, aspartate aminotransferase; BP, blood pressure; eGFR, estimated glomerular filtration rate; HDL, high-density lipoprotein cholesterol; LDL, low-density lipoprotein cholesterol.

\section{Results}

\section{Baseline Characteristics}

A total of 9,534 participants (7,474 men and 2,060 women) older than 20 years and having baseline eGFR $>60 \mathrm{~mL} / \mathrm{min} / 1.73 \mathrm{~m}^{2}$ were included. Those with missing data, baseline eGFR $<60 \mathrm{~mL} / \mathrm{min} / 1.73 \mathrm{~m}^{2}$, or AKI $(n=$ $14,178)$ were excluded. We classified serum uric acid level into 4 groups: first quartile, $<5.1 \mathrm{mg} / \mathrm{dL}$; second quartile, 5.1 to $<6.2 \mathrm{mg} / \mathrm{dL}$; third quartile, 6.2 to $<7.2 \mathrm{mg} / \mathrm{dL}$; and fourth quartile, $7.2 \mathrm{mg} / \mathrm{dL}$ or more. The second, third, and fourth quartile groups had a significantly higher proportion of men (Table 1). A significant continuous increase of weight, height, BMI, waist circumference, systolic BP, diastolic BP, proportion of hypertension, dyslip- idemia, smoking, alcohol consumption, serum Cr, BUN, total cholesterol, triglycerides, LDL, AST, ALT, alkaline phosphatase, and hemoglobin was observed, according to an increase in serum uric acid level quartiles. Inversely, eGFR and HDL significantly decreased along with increasing serum uric quartiles. No difference was observed in FPG among the quartiles (Table 1).

\section{Baseline Serum Uric Acid on Changes of Renal and Metabolic Outcomes}

We evaluated the changes of renal and metabolic parameters among baseline uric quartiles at the end of the study. Differences were found in changes between quartiles in all parameters, except BMI, waist circumference, and systolic BP (Table 2). Diastolic BP, serum Cr, AST, 
Table 2. Baseline uric acid on changes of clinical parameters at the end of the study

\begin{tabular}{|c|c|c|c|c|c|}
\hline & \multicolumn{4}{|l|}{ Uric acid } & \multirow[t]{2}{*}{$p$ value } \\
\hline & $<5.1 \mathrm{mg} / \mathrm{dL}$ & $\begin{array}{l}5.1 \text { to } \\
<6.2 \mathrm{mg} / \mathrm{dL}\end{array}$ & $\begin{array}{l}6.2 \text { to } \\
<7.2 \mathrm{mg} / \mathrm{dL}\end{array}$ & $\geq 7.2 \mathrm{mg} / \mathrm{dL}$ & \\
\hline$N$ & 2,393 & 2,336 & 2,270 & 2,535 & \\
\hline BMI, $\mathrm{kg} / \mathrm{m}^{2}$ & $0.72 \pm 1.84$ & $0.69 \pm 1.79$ & $0.69 \pm 1.68$ & $0.61 \pm 1.79$ & 0.138 \\
\hline Waist circumference, $\mathrm{cm}$ & $2.07 \pm 7.71$ & $2.33 \pm 8.03$ & $2.34 \pm 9.97$ & $2.51 \pm 7.35$ & 0.328 \\
\hline Systolic BP, mm Hg & $1.15 \pm 14.63$ & $0.67 \pm 15.4$ & $1.22 \pm 15.63$ & $0.26 \pm 16.43$ & 0.109 \\
\hline Diastolic BP, mm Hg & $-1.26 \pm 9.98$ & $-1.19 \pm 10.6$ & $-0.89 \pm 10.59$ & $-1.84 \pm 11.77$ & 0.021 \\
\hline $\mathrm{eGFR}, \mathrm{mL} / \mathrm{min} / 1.73 \mathrm{~m}^{2}$ & $-0.27 \pm 9.26$ & $0.57 \pm 9.43$ & $0.88 \pm 9.48$ & $1.58 \pm 9.77$ & $<0.001$ \\
\hline eGFR change per year, $\mathrm{mL} / \mathrm{min} / 1.73 \mathrm{~m}^{2} /$ year $(95 \% \mathrm{CI})$ & $-0.04(-0.11,0.02)$ & $0.1(0.03,0.16)$ & $0.15(0.08,0.21)$ & $0.26(0.2,0.33)$ & $<0.001$ \\
\hline Serum Cr, mg/dL & $-0.03 \pm 0.1$ & $-0.03 \pm 0.21$ & $-0.04 \pm 0.12$ & $-0.05 \pm 0.11$ & $<0.001$ \\
\hline $\mathrm{BUN}, \mathrm{mg} / \mathrm{dL}$ & $0.64 \pm 3.15$ & $0.32 \pm 3.4$ & $0.21 \pm 3.41$ & $-0.1 \pm 3.29$ & $<0.001$ \\
\hline Fasting plasma glucose, $\mathrm{mg} / \mathrm{dL}$ & $-0.53 \pm 27.4$ & $1.9 \pm 27.23$ & $4.05 \pm 27.11$ & $6.35 \pm 30.12$ & $<0.001$ \\
\hline Total cholesterol, mg/dL & $11.3 \pm 41.3$ & $5.92 \pm 43.08$ & $2.63 \pm 42.48$ & $-1.96 \pm 47.36$ & $<0.001$ \\
\hline Triglyceride, mg/dL & $12.86 \pm 91.54$ & $7.8 \pm 114.28$ & $4.28 \pm 120.11$ & $-12.46 \pm 159.45$ & $<0.001$ \\
\hline $\mathrm{HDL}, \mathrm{mg} / \mathrm{dL}$ & $2.84 \pm 11.77$ & $1.69 \pm 11.56$ & $1.22 \pm 11.17$ & $1.23 \pm 11.85$ & $<0.001$ \\
\hline $\mathrm{LDL}, \mathrm{mg} / \mathrm{dL}$ & $5.66 \pm 38.02$ & $2.82 \pm 39.4$ & $0.71 \pm 40.15$ & $-0.41 \pm 45.65$ & $<0.001$ \\
\hline AST, U/L & $0.15 \pm 17.52$ & $-0.6 \pm 22.7$ & $-0.76 \pm 24.62$ & $-2.16 \pm 34.99$ & 0.017 \\
\hline ALT, U/L & $-0.44 \pm 20.68$ & $-1.23 \pm 24.75$ & $-2.6 \pm 35.12$ & $-3.58 \pm 37.81$ & 0.002 \\
\hline Alkaline phosphatase, U/L & $-0.13 \pm 17.81$ & $-3.15 \pm 17.09$ & $-3.26 \pm 17.9$ & $-4.12 \pm 19.04$ & $<0.001$ \\
\hline Hemoglobin, g/dL & $-0.01 \pm 1.04$ & $-0.04 \pm 0.89$ & $-0.08 \pm 0.93$ & $-0.09 \pm 0.92$ & 0.018 \\
\hline
\end{tabular}

Data are presented as mean $\pm \mathrm{SD}$, and number with percentage. ALT, alanine transaminase; AST, aspartate aminotransferase; BP, blood pressure; eGFR, estimated glomerular filtration rate; CI, confidence interval; HDL, high-density lipoprotein cholesterol; LDL, low-density lipoprotein cholesterol.

ALT, alkaline phosphatase, and hemoglobin decreased with highest magnitude at the fourth quartile. While the uric quartiles were increasing, eGFR and FPG rose consecutively, which had an opposite direction. BUN, total cholesterol, LDL, HDL, and triglycerides increased as well, but higher magnitudes were observed at the lower quartiles (Table 2). We also evaluated the annual changes of eGFR in mean with $95 \%$ CIs. Slightly significant changes were found from first to fourth quartiles, which were $-0.04(-0.11,0.02), 0.1(0.03,0.16), 0.15(0.08,0.21)$, and $0.26(0.2,0.33) \mathrm{mL} / \mathrm{min} / 1.73 \mathrm{~m}^{2}$, respectively $(p<0.001$, Table 2).

Progression of kidney function over time is presented in Figure 1. Mean eGFR according to serum uric acid level quartiles fluctuated each year between 80 and $100 \mathrm{~mL} /$ min per $1.73 \mathrm{~m}^{2}$. The lower quartiles always had higher mean eGFR than the higher quartiles throughout the study (Fig. 1).

\section{Cox Regression Model}

Cox regression analysis revealed a significant association of serum uric acid level quartiles with impaired renal function in the whole population as the unadjusted $\mathrm{HR}$ in the second, third, and fourth quartiles were 2.1 (95\% CI,
1.39-3.17), 2.390 (95\% CI, 1.6-3.59), and 3.94 (95\% CI, 2.71-5.74), respectively, when compared with serum uric in the first quartile (Table 3). After adjusting in Model 1, including age, BMI, sex, type 2 diabetes, hypertension, smoking, and alcohol consumption, the respective HRs persisted significantly in the second, third, and fourth quartiles at HR 1.99 (95\% CI, 1.29-3.06), 2.36 (95\% CI, 1.52-3.69), and 3.87 (95\% CI, 2.51-5.96), respectively (Table 3). For Model 2, including age, BMI, sex, type 2 diabetes, hypertension, triglyceride, HDL, AST, alkaline phosphatase, hemoglobin, smoking, alcohol consumption, and exercise, the respective HRs persisted significantly in the second, third, and fourth quartiles at HR 2.04 (95\% CI, 1.32-3.15), 2.46 (95\% CI, 1.57-3.86) and 4.09 (95\% CI, 2.63-6.35), respectively (Table 3).

After performing Cox regression model on each sex, the relationship between degree of uric acid quartiles and magnitude of impaired renal function also persisted by either univariate or multivariate analysis. However, a significant relationship could be observed only in the fourth quartiles among female (Table 3), as well as in the third and fourth quartiles in the male population (Table 3 ). 
Table 3. Hazard ratio of impaired renal function

\begin{tabular}{|c|c|c|c|c|c|c|}
\hline \multirow[t]{2}{*}{ Total population } & \multicolumn{2}{|l|}{ Univariate } & \multicolumn{4}{|l|}{ Multivariate } \\
\hline & $\begin{array}{l}\text { crude HR } \\
(95 \% \mathrm{CI})\end{array}$ & $p$ value & $\begin{array}{l}\text { adjusted HR } \\
(95 \% \mathrm{CI})\end{array}$ & $p$ value & $\begin{array}{l}\text { adjusted HR } \\
(95 \% \mathrm{CI})\end{array}$ & $p$ value \\
\hline First quartile uric acid $(<5.1)$ & Reference & 1 & Reference & 1 & Reference & 1 \\
\hline Second quartile uric acid $(5.1$ to $<6.2)$ & $2.1(1.39,3.17)$ & $<0.001$ & $1.99(1.29,3.06)$ & 0.002 & $2.04(1.32,3.15)$ & 0.001 \\
\hline \multicolumn{7}{|l|}{ Female } \\
\hline First quartile uric acid $(<4)$ & Reference & 1 & Reference & 1 & Reference & 1 \\
\hline Second quartile uric acid ( 4 to $<4.7$ ) & $1.95(0.6,6.32)$ & 0.268 & $1.82(0.56,5.93)$ & 0.319 & $1.85(0.57,6.04)$ & 0.307 \\
\hline Third quartile uric acid $(4.7$ to $<5.4)$ & $2.5(0.78,7.96)$ & 0.122 & $2.14(0.67,6.88)$ & 0.201 & $2.22(0.69,7.19)$ & 0.181 \\
\hline Fourth quartile uric acid $(\geq 5.4)$ & $4.74(1.63,13.76)$ & 0.004 & $3.33(1.1,10.09)$ & 0.034 & $3.53(1.15,10.87)$ & 0.028 \\
\hline Third quartile uric acid $(6.5$ to $<7.5)$ & $1.73(1.17,2.56)$ & 0.006 & $1.75(1.17,2.61)$ & 0.006 & $1.78(1.19,2.66)$ & 0.005 \\
\hline Fourth quartile uric acid $(\geq 7.5)$ & $2.74(1.9,3.96)$ & $<0.001$ & $2.75(1.88,4.01)$ & $<0.001$ & $2.84(1.93,4.18)$ & $<0.001$ \\
\hline
\end{tabular}

Model 1 adjusted by age, BMI, sex, type 2 diabetes, hypertension, smoking, and alcohol consumption. Model 2 adjusted by age, BMI, sex, type 2 diabetes, hypertension, triglyceride, HDL, AST, alkaline phosphatase, hemoglobin, smoking, alcohol consumption, and exercise. All variables are at the baseline level. HR, hazard ratio; CI, confidence interval; AST, aspartate aminotransferase; HDL, high-density lipoprotein cholesterol.

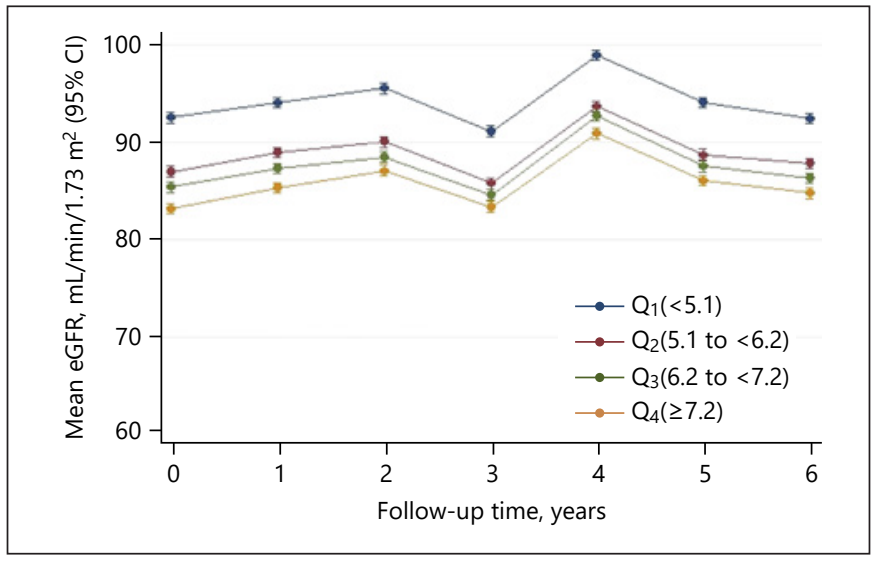

Fig. 1. Progression of kidney function over time according to serum uric acid level quartiles. Progression of kidney function over time is illustrated in annual mean estimated glomerular filtration rate (eGFR) with 95\% confidence intervals (CI) according to serum uric acid level quartiles. The annual changes of mean eGFR with $95 \%$ CI from first to fourth quartiles were $-0.04(-0.11,0.02)$, $0.1(0.03,0.16), 0.15(0.08,0.21)$, and $0.26(0.2,0.33)$, respectively $(p<0.001$; Table 2$)$.

\section{Renal Survival Curve}

The Kaplan-Meier curve between progression to impaired renal function and uric acid quartiles over a 6-year period showed a higher renal survival in the lesser quartile group, with rising differences in survival in each group after time passed (log-rank test $<0.001$; Fig. 2). At the end of the study, renal survival estimates for first to fourth quartiles were $98.5,96.9,96.5$, and $94.3 \%$ respectively (Fig. 2).

\section{Serum Uric Acid and Declined eGFR}

At the end of the study, simple linear regression analysis showed that eGFR negatively correlated with baseline serum uric ( $r=-0.213, p<0.001$; Fig. 3 ), with a stronger negative correlation among females than among males $(r=-0.175, p<0.001$ vs. $r=-0.133, p<0.001$; Fig. 3$)$. Thus, for every $1 \mathrm{mg} / \mathrm{dL}$ increase in serum uric acid, eGFR would decline $2.1 \mathrm{~mL} / \mathrm{min}$ per $1.73 \mathrm{~m}^{2}$.

The cumulative incidence (Fig. 4) and rate per 1,000 person-years (Table 4 ) of impaired renal function according to serum uric levels increased consecutively from the first to fourth quartiles for each sex. Notably, sex differences were found, in which the incidences were higher in all quartiles among males than among females (Table 4; Fig. 4). 


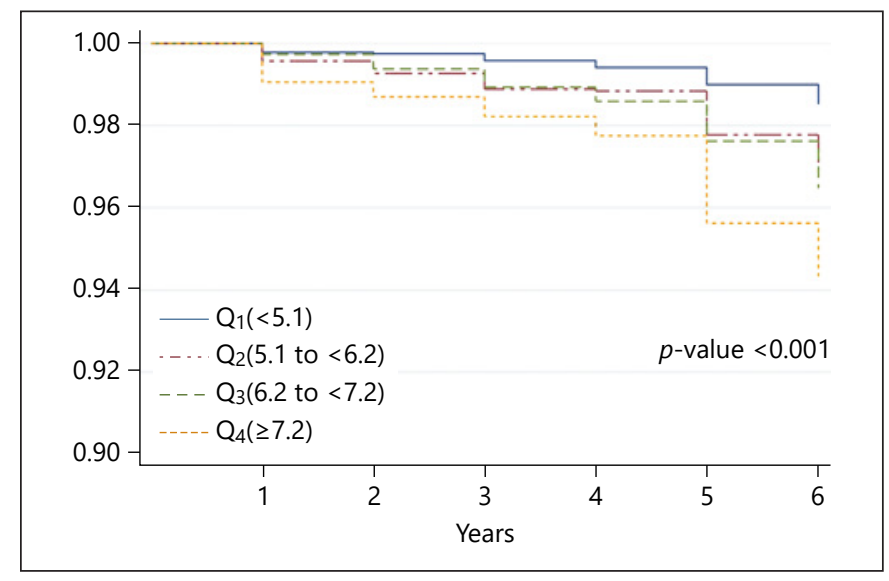

Fig. 2. Kaplan-Meier curve of renal survival in total population according to serum uric acid level quartiles. Kaplan-Meier survival estimates for renal survival to 6 years according to serum uric acid level quartiles (log-rank test $<0.001)$. The defined term of renal survival is progression to CKD stage III based on decreased glomerular filtration rate criteria. At the end of the study, renal survival estimates for first to fourth quartiles were 98.5, 96.9, 96.5, and $94.3 \%$, respectively.

\section{Discussion}

The 6-year prospective cohort study revealed the independent association of serum uric acid levels with the incidence of impaired renal function and renal progression in a Thai community-based population. These findings support the idea that uric acid might be implicated in the pathogenesis of CKD.

Study results correlated with a meta-analysis in 2014 demonstrating an association between serum uric acid level and incidence of CKD in middle-aged populations, and 10 of 15 cohorts were conducted in Asian countries [21]. A significant independent association between uric acid and risk of CKD development was also found in another systematic review and meta-analysis based on cohort studies [22]. Furthermore, increased serum uric acid was associated with renal disease progression in crosssectional and longitudinal studies in Thailand, Japan, Europe, and the USA [14-18]. A study by Obermayr et al. [17], a 7-year longitudinal cohort study in 17,735 healthy Viennese, showed that an increase in serum uric acid by $2 \mathrm{mg} / \mathrm{dL}$ was an independent risk factor for CKD (OR = 1.69 ; 95\% CI, 1.59-1.80).

Animal model studies support that hyperuricemia leads to renal progression by activating renin-angiotensin, various inflammatory mediators, cyclooxygenase- 2 systems, and microvascular changes leading to endothe-

Hyperuricemia and Impaired Renal Function

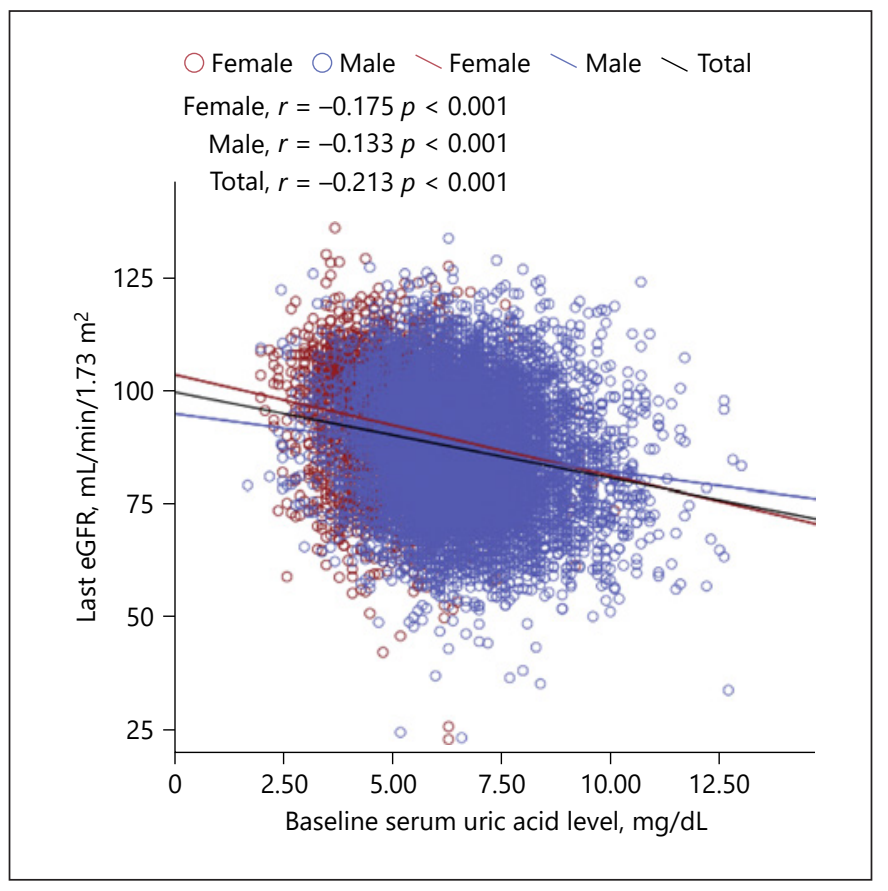

Fig. 3. Linear regression curve between baseline serum uric acid level and estimated glomerular filtration rate (eGFR) outcome. Correlation of baseline serum uric acid levels with eGFR. Serum uric acid levels correlated significantly in a negative manner among subjects overall $(r=-0.213, p<0.001)$. Higher degree of inverse correlation was found among females $(r=-0.175, p<0.001)$ than among males $(r=-0.133, p<0.001)$.

lial dysfunction causing systemic hypertension, glomerular hypertrophy, and increased intraglomerular pressure $[12,13,23-25]$. Some evidence also suggests that uric acid causes renal interstitial fibrosis with collagen deposition and macrophage infiltration as well as arteriolopathy of the preglomerular vessels [26, 27]. Moreover, an animal study of established kidney disease reported that reduced serum uric acid levels from the hyperuricemic state improved BP, proteinuria, and degrees of glomerular, tubulointerstitial, and vascular defects [28]. On the other hand, some authorities believe that uric acid by itself does not cause renal damage or is a true risk factor for kidney diseases [29-32], because many confounding factors are related to GFR decline in clinical practice.

Some studies have noted the sex-differentiated effect between uric acid and CKD progression [17]. In this study, the result after distinguishing between sexes in the Cox regression analysis, cumulative incidence of impaired renal function and linear regression illustrated the similar trend of association among males and females at different magnitudes. The HRs and correlation coeffi- 


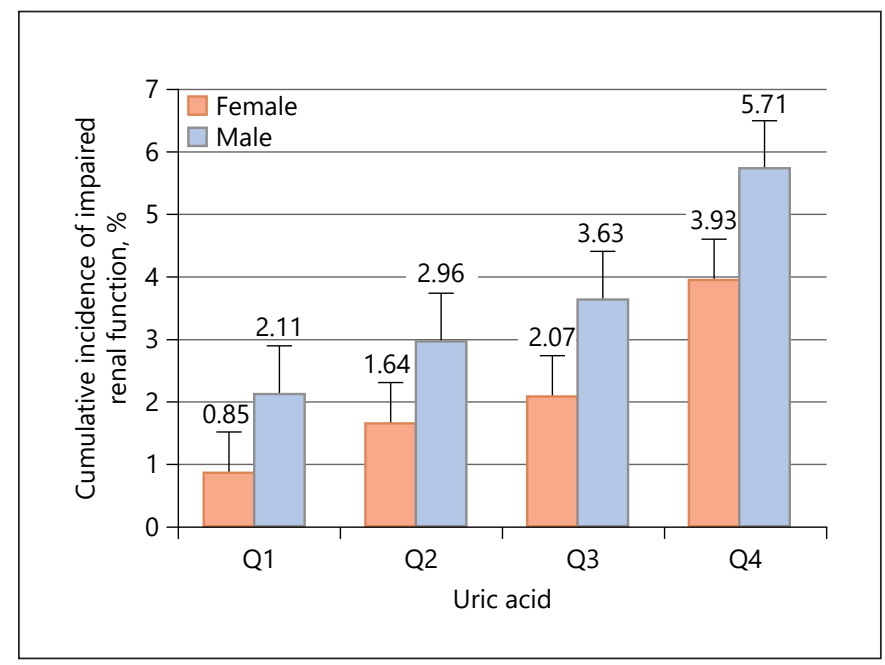

Fig. 4. Incidence of impaired renal function according to serum uric acid level quartiles categorized by sex. Bar chart for incidence of impaired renal function. Sex differences were found in all quartiles with higher percentage of incidence among males than among females.

cient of uric acid and renal outcomes were profoundly stronger in female group than in male group and total population, but the cumulative incidences among females were totally lower than those among males in all quartiles. It could be explained by the higher proportion of females in first quartiles exhibiting higher eGFR at baseline that could meet the impaired renal function criteria more slowly than those in the male group.

In comparison with the Asian populations, baseline serum uric acid according to sex in this study was similar to the others. The mean serum uric acid was significantly higher among Asian men than among women; however, similar values were found overall in the Southeast Asian population [15, 33-35].

All parameters at baseline seemed worse in the higher quartiles when compared with the lower quartiles, especially hypertension and BP (Table 1). Our previous study in a Thai army population [9] and other related studies $[28,36]$ showed an association between serum uric acid and BP. However, the change in systolic and diastolic BP of the fourth quartile was the least similar in manner among other parameters, such as triglycerides, total cholesterol, LDL, AST, ALT, and alkaline phosphatase (Table 2). We hypothesized that individuals at the fourth quartile, having the worst metabolic profiles at baseline, had a higher chance to receive either pharmacological treatment or lifestyle modification, than those at the low-
Table 4. Unadjusted incidence of impaired renal function, along with $95 \%$ CIs categorized by sex

\begin{tabular}{lcll}
\hline $\begin{array}{l}\text { Uric acid baseline } \\
(\mathrm{mg} / \mathrm{dL})\end{array}$ & $\begin{array}{l}\text { Events, } \\
n\end{array}$ & $\begin{array}{l}\text { Person-time, } \\
\text { years }\end{array}$ & $\begin{array}{l}\text { Rate per 1,000 } \\
\text { person-years } \\
(95 \% \mathrm{CI})\end{array}$ \\
\hline $\begin{array}{l}\text { Female } \\
\mathrm{Q}_{1}(<4)\end{array}$ & 4 & 2,773 & $1.44(0.54,3.84)$ \\
$\mathrm{Q}_{2}(4$ to $<4.7)$ & 9 & 3,216 & $2.80(1.46,5.38)$ \\
$\mathrm{Q}_{3}(4.7$ to $<5.4)$ & 10 & 2,804 & $3.57(1.92,6.63)$ \\
$\mathrm{Q}_{4}(\geq 5.4)$ & 22 & 3,246 & $6.78(4.46,10.29)$ \\
\hline Total $($ female $)$ & 45 & 12,039 & $3.74(2.79,5.01)$ \\
\hline Male & & & \\
$\mathrm{Q}_{1}(<5.7)$ & 38 & 10,475 & $3.63(2.64,4.99)$ \\
$\mathrm{Q}_{2}(5.7$ to $<6.5)$ & 52 & 10,189 & $5.10(3.89,6.70)$ \\
$\mathrm{Q}_{3}(6.5$ to $<7.5)$ & 71 & 11,349 & $6.26(4.96,7.89)$ \\
$\mathrm{Q}_{4}(\geq 7.5)$ & 112 & 11,290 & $9.92(8.24,11.94)$ \\
\hline Total $($ male $)$ & 273 & 43,303 & $6.30(5.60,7.10)$ \\
\hline
\end{tabular}

The defined term of impaired renal function event is progression to CKD, stage III, which is based on decreased GFR criteria.

er quartiles. Therefore, the fourth group had improved laboratory results. Absence of pharmacological parameters and lifestyle modification measurement constituted limitations of this hypothesis. On the other hand, increased FPG annually in higher quartiles opposed the hypothesis. Related studies in Asian populations have revealed associations of insulin resistance, plasma glucose, impaired fasting glucose, and type 2 diabetes with higher serum uric acid level, which could explain this result [37, 38].

Significant differences in mean eGFR change were found between the quartiles. However, annual mean eGFR changes had a minimal progression, which was $<1$ $\mathrm{mL} / \mathrm{min} / 1.73 \mathrm{~m}^{2}$ per year among all quartiles (Table 2). Similarly, progression of eGFR according to serum uric acid level quartiles in Figure 1 showed fluctuations around $90 \mathrm{~mL} / \mathrm{min}$ per $1.73 \mathrm{~m}^{2}$ each year (Fig. 1). These results indicated that most of the subjects were at low risk and had a good renal function. Those who had higher serum uric acid levels always had poorer eGFR and higher risk to meet the impaired renal function criteria, defined by eGFR $<60 \mathrm{~mL} / \mathrm{min} / 1.73 \mathrm{~m}^{2}$ over 3 months (Tables 2-4; Fig. 1-3).

The limited data suggest urate-lowering therapy to prevent kidney damage, and benefits of treatment of hyperuricemia were not observed at all time points of study [39]. Currently, the meta-analysis of 12 randomized con- 
trol trials with 832 CKD participants supports the hypothesis that the risk of worsening of kidney function was significantly decreased in the uric acid-lowering therapy and risk for developing CKD groups [40]. Larger randomized controlled trials are required to study the effect of uric acid-lowering therapy on CKD progression.

The strength of this study included the large number of participants, carefully collected data, and all laboratory measurements being made in 1 laboratory. Several potential limitations of this study were noted. First, information on urinalysis, renal imaging, and pathology were unavailable. Subjects presenting baseline eGFR of $60 \mathrm{~mL} /$ min per $1.73 \mathrm{~m}^{2}$ or more were enrolled, and non-GFRbased evidence of CKD were unidentified. Second, information on routinely used medications, such as anti-hypertensive agents or uric acid-lowering agents, associated with uric acid metabolism were unavailable. Finally, the generalizability of this study may have been limited by selection bias of the relatively higher proportion of men than women subjects and those mainly in the Thai army population.

\section{Conclusion}

In conclusion, our study suggests that serum uric acid levels were independently associated with the incidence of impaired renal function and renal progression in a Thai community-based population. Early detection and intervention of hyperuricemia should be concerned as a part of CKD prevention.

\section{Acknowledgements}

We thank the Armed Forces Research Institute of Medical Sciences and medical staff from the Department of Medicine, Phramongkutklao Hospital and College of Medicine, Bangkok, Thailand, for support with enrolling patients and collecting data. The authors wish to acknowledge Ms. Dollapas Punpanich for statistical analysis.

\section{Statement of Ethics}

The study protocol was approved by the Institutional Review Board of Royal Thai Army Medical Department's committee on human research, and written informed consent was obtained from all patients.

\section{Conflict of Interest Statement}

The authors declare that no potential conflict of interest exists.

\section{Funding Sources}

This study was supported by a grant from the Department of Medicine, Phramongkutklao Hospital.

\section{Author Contributions}

N.A., B.S., and P.W. collected the data and reviewed the literature. N.A. and B.S. provided valuable input on study design and data collection, drafted the article, and revised it critically. O.S. provided literature review. All authors read and approved the manuscript and met the criteria for authorship.

\section{References}

1 Go AS, Chertow GM, Fan D, McCulloch CE, Hsu CY. Chronic kidney disease and the risks of death, cardiovascular events, and hospitalization. N Engl J Med. 2004;351(13):1296305.

2 Hill NR, Fatoba ST, Oke JL, Hirst JA, O'Callaghan CA, Lasserson DS, et al. Global prevalence of chronic kidney disease: a systematic review and meta-analysis. PLoS One. 2016;11(7): $\mathrm{e} 0158765$.

3 Satirapoj B, Supasyndh O, Mayteedol N, Punpanich D, Chaiprasert A, Nata N, et al. Obesity and its relation to chronic kidney disease: a population-based, cross-sectional study of a Thai army population and relatives. Nephrology. 2013; 18(3):229-34.

4 Matsushita K, van der Velde M, Astor BC, Woodward M, Levey AS, de Jong PE, et al., Chronic Kidney Disease Prognosis Consortium. Association of estimated glomerular fil-

Hyperuricemia and Impaired Renal Function tration rate and albuminuria with all-cause and cardiovascular mortality in general population cohorts: a collaborative meta-analysis. Lancet. 2010;375(9731):2073-81.

5 National Kidney Foundation. K/DOQI clinical practice guidelines for chronic kidney disease: evaluation, classification, and stratification. Am J Kidney Dis. 2002;39(2 Suppl 1):S1-266.

6 Cirillo P, Sato W, Reungjui S, Heinig M, Gersch M, Sautin Y, et al. Uric acid, the metabolic syndrome, and renal disease. J Am Soc Nephrol. 2006;17(12 Suppl 3):S165-8.

7 Edwards NL. The role of hyperuricemia and gout in kidney and cardiovascular disease. Cleve Clin J Med. 2008;75(Suppl 5):S13-6.

8 Masuo K, Kawaguchi H, Mikami H, Ogihara T, Tuck ML. Serum uric acid and plasma norepinephrine concentrations predict subsequent weight gain and blood pressure elevation. Hypertension. 2003;42(4):474-80.
9 Ouppatham S, Bancha S, Choovichian P. The relationship of hyperuricemia and blood pressure in the Thai army population. J Postgrad Med. 2008;54(4):259-62.

10 Fessel WJ. Renal outcomes of gout and hyperuricemia. Am J Med. 1979;67(1):74-82.

11 Gonick HC, Rubini ME, Gleason IO, Sommers SC. The renal lesion in gout. Ann Intern Med. 1965;62:667-74.

12 Kang DH, Nakagawa T, Feng L, Watanabe S, Han L, Mazzali M, et al. A role for uric acid in the progression of renal disease. J Am Soc Nephrol. 2002;13(12):2888-97.

13 Kanellis J, Kang DH. Uric acid as a mediator of endothelial dysfunction, inflammation, and vascular disease. Semin Nephrol. 2005;25(1):39-42.

14 Chonchol M, Shlipak MG, Katz R, Sarnak MJ, Newman AB, Siscovick DS, et al. Relationship of uric acid with progression of kidney disease. Am J Kidney Dis. 2007;50(2):239-47. 
15 Domrongkitchaiporn S, Sritara P, Kitiyakara C, Stitchantrakul W, Krittaphol V, Lolekha P, et al. Risk factors for development of decreased kidney function in a Southeast Asian population: a 12-year cohort study. J Am Soc Nephrol. 2005;16(3):791-9.

16 Iseki K, Oshiro S, Tozawa M, Iseki C, Ikemiya Y, Takishita S. Significance of hyperuricemia on the early detection of renal failure in a cohort of screened subjects. Hypertens Res. 2001;24(6):691-7.

17 Obermayr RP, Temml C, Knechtelsdorfer M, Gutjahr G, Kletzmayr J, Heiss S, et al. Predictors of new-onset decline in kidney function in a general middle-European population. Nephrol Dial Transplant. 2008;23(4):1265-73.

18 Weiner DE, Tighiouart H, Elsayed EF, Griffith JL, Salem DN, Levey AS. Uric acid and incident kidney disease in the community. J Am Soc Nephrol. 2008;19(6):1204-11.

19 American Diabetes Association. Clinical practice recommendations 2005. Diabetes Care. 2005;28(Suppl 1):S1-79.

20 Chobanian AV, Bakris GL, Black HR, Cushman WC, Green LA, Izzo JL Jr, et al. The seventh report of the joint national committee on prevention, detection, evaluation, and treatment of high blood pressure: the JNC 7 report. JAMA. 2003;289(19):2560-72.

21 Zhu P, Liu Y, Han L, Xu G, Ran JM. Serum uric acid is associated with incident chronic kidney disease in middle-aged populations: a meta-analysis of 15 cohort studies. PLoS One. 2014;9(6):e100801.

22 Li L, Yang C, Zhao Y, Zeng X, Liu F, Fu P. Is hyperuricemia an independent risk factor for newonset chronic kidney disease? A systematic review and meta-analysis based on observational cohort studies. BMC Nephrol. 2014;15:122.

23 Johnson RJ, Rodriguez-Iturbe B, Kang DH, Feig DI, Herrera-Acosta J. A unifying pathway for essential hypertension. Am J Hypertens. 2005;18(3):431-40.
24 Kanellis J, Watanabe S, Li JH, Kang DH, Li P, Nakagawa T, et al. Uric acid stimulates monocyte chemoattractant protein-1 production in vascular smooth muscle cells via mitogen-activated protein kinase and cyclooxygenase-2. Hypertension. 2003;41(6):1287-93.

25 Kang DH, Nakagawa T. Uric acid and chronic renal disease: possible implication of hyperuricemia on progression of renal disease. Semin Nephrol. 2005;25(1):43-9.

26 Mazzali M, Kanellis J, Han L, Feng L, Xia YY, Chen Q, et al. Hyperuricemia induces a primary renal arteriolopathy in rats by a blood pressure-independent mechanism. Am J Physiol Renal Physiol. 2002;282(6):F991-7.

27 Rao GN, Corson MA, Berk BC. Uric acid stimulates vascular smooth muscle cell proliferation by increasing platelet-derived growth factor A-chain expression. J Biol Chem. 1991; 266(13):8604-8.

28 Johnson RJ, Kang DH, Feig D, Kivlighn S, Kanellis J, Watanabe S, et al. Is there a pathogenetic role for uric acid in hypertension and cardiovascular and renal disease? Hypertension. 2003;41(6):1183-90.

29 Asokan D, Kalaiselvi P, Muhammed Farooq S, Varalakshmi P. Calcium oxalate monohydrate binding protein: a diagnostic biomarker for calcium oxalate kidney stone formers. Urol Res. 2004;32(5):357-61.

30 Hunsicker LG, Adler S, Caggiula A, England BK, Greene T, Kusek JW, et al. Predictors of the progression of renal disease in the Modification of Diet in Renal Disease Study. Kidney Int. 1997;51(6):1908-19.

31 Rosenfeld JB. Effect of long-term allopurinol administration on serial GFR in normotensive and hypertensive hyperuricemic subjects. Adv Exp Med Biol. 1974;41:581-96.

32 Sturm G, Kollerits B, Neyer U, Ritz E, Kronenberg F, MMKD Study Group.. Uric acid as a risk factor for progression of non-diabetic chronic kidney disease? The Mild to Moder- ate Kidney Disease (MMKD) study. Exp Gerontol. 2008;43(4):347-52.

33 Jaipakdee J, Jiamjarasrangsri W, Lohsoonthorn V, Lertmaharit S. Prevalence of metabolic syndrome and its association with serum uric acid levels in Bangkok Thailand. Southeast Asian J Trop Med Public Health. 2013;44(3):512-22.

34 Subramani S, Khor SE, Livingstone BI, Kulkarni UV. Serum uric acid levels and its association with age-related macular degeneration (ARMD). Med J Malaysia. 2010;65(1): 36-40.

35 Dao HH, Harun-Or-Rashid M, Sakamoto J. Body composition and metabolic syndrome in patients with primary gout in Vietnam. Rheumatology. 2010;49(12):2400-7.

36 Mazzali M, Hughes J, Kim YG, Jefferson JA, Kang DH, Gordon KL, et al. Elevated uric acid increases blood pressure in the rat by a novel crystal-independent mechanism. Hypertension. 2001;38(5):1101-6.

37 Chou P, Lin KC, Lin HY, Tsai ST. Gender differences in the relationships of serum uric acid with fasting serum insulin and plasma glucose in patients without diabetes. J Rheumatol. 2001;28(3):571-6.

38 Nakanishi N, Okamoto M, Yoshida H, Matsuo Y, Suzuki K, Tatara K. Serum uric acid and risk for development of hypertension and impaired fasting glucose or type II diabetes in Japanese male office workers. Eur J Epidemiol. 2003;18(6):523-30.

39 Sampson AL, Singer RF, Walters GD. Uric acid lowering therapies for preventing or delaying the progression of chronic kidney disease. Cochrane Database Syst Rev. 2017; 10(10):CD009460

40 Liu X, Zhai T, Ma R, Luo C, Wang H, Liu L. Effects of uric acid-lowering therapy on the progression of chronic kidney disease: a systematic review and meta-analysis. Ren Fail. 2018;40(1):289-97. 